
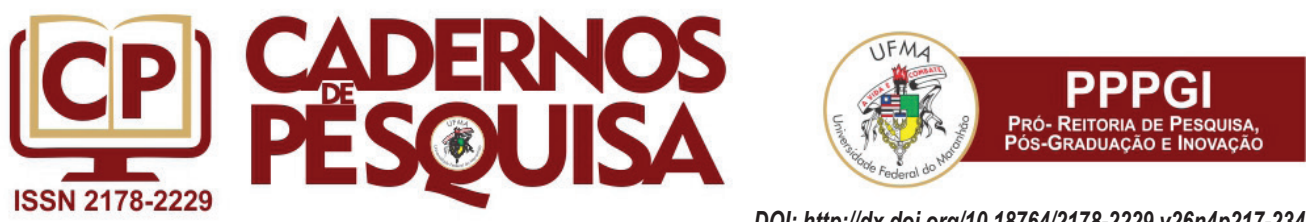

DOl: http://dx.doi.org/10.18764/2178-2229.v26n4p217-234

\title{
PROGRAMA DE PÓS-GRADUAÇÃO EM EDUCAÇÃO PROFISSIONAL E TECNOLÓGICA (PROFEPT): conquistas, perspectivas e desafios
}

\author{
PROFESSIONAL AND TECHNOLOGICAL EDUCATION GRADUATE \\ PROGRAM (PROFEPT): achievements, perspectives and challenges \\ PROGRAMA DE POSGRADO EN EDUCACIÓN PROFESIONAL Y \\ TECNOLÓGICA (PROFEPT): logros, perspectivas y desafíos
}

Francisco das Chagas Silva Souza ${ }^{1}$

\begin{abstract}
RESUMO
Neste artigo, discutimos a criação do Programa de Pós-Graduação em Educação Profissional e Tecnológica (ProfEPT), Mestrado Profissional em Rede Nacional, como uma medida voltada à formação continuada de servidores da Rede Federal de Educação Profissional, Científica e Tecnológica e de professores da Educação Básica. Trata-se de uma pesquisa bibliográfica e documental, com uso de dados estatísticos. Concluímos que a criação do ProfEPT representa um avanço para a Rede e para a Educação Básica, embora essa conquista é acompanhada de desafios que envolvem a formação docente para a Educação Profissional e Tecnológica, a prática da interdisciplinaridade, a elaboração de produtos educacionais alicerçados nas bases conceituais da EPT, entre outras limitações a serem avaliadas e superadas pelos docentes do Programa.
\end{abstract}

Palavras-chave: Educação Profissional e Tecnológica. Mestrado Profissional. Formação continuada. Produtos educacionais. Interdisciplinaridade.

\begin{abstract}
ABSTRAC
In this article, we discuss the creation of the Postgraduate Program in Professional and Technological Education (ProfEPT), Professional Master in National Network, as a measure aimed at the continuing education of servers belonging to the Federal Network of Professional, Scientific and Technological Education and Basic Education teachers. It is a bibliographic and documentary research, using statistical data. We conclude that the ProfEPT creation represents a breakthrough for the Network and for Basic Education, but this achievement is accompanied by challenges involving teacher education for Professional and Technological Education, the practice of interdisciplinarity, the development of educational products based on conceptual basis of VTE, among other limitations to be evaluated and overcome by the teachers of the Program.
\end{abstract}

Keywords: Professional and Technological Education. Professional Master's degree. Continuing Education. Educational products. Interdisciplinarity.

\section{RESUMEN}

En este artículo, discutimos la creación del Programa de Posgrado en Educación Profesional y Tecnologica (ProfEPT), Maestría Profesional en Red Nacional, como una medida dirigida a la educación continua de los servidores de la Red Federal de Educación Profesional, Cientifica y Tecnológica y docentes de educación básica. Es una investigación bibliográfica y documental, que utiliza datos estadísticos. Llegamos a la conclusión de que la creación de ProfEPT representa un gran avance para la Red y para la educación básica, pero este logro es acompañado de desafíos que involucran la formación del profesorado para la Educación Vocacional y Tecnologica, la práctica de la interdisciplinariedad, el desarrollo de productos educativos basados en base conceptual de la EPT, entre otras limitaciones para ser evaluadas y superadas por los docentes del Programa.

1 Instituto Federal de Educação, Ciência e Tecnologia do Rio Grande do Norte (IFRN). Natal - RN, Brasil. ORCID: http://orcid.org/00000002-9721-9812. E-mail: chagas.souza@ifrn.edu.br

Artigo recebido em setembro de 2019. Aprovado em novembro de 2019.

Cad. Pesq., v. 26, n. 4, out./dez., 2019. 
Palabras clave: Educación profesional y tecnológica. Máster profesional. Educación continua Productos educativos Interdisciplinariedad.

\section{Introdução}

A criação, em 1909, das Escolas de Aprendizes Artífices, pelo então presidente Nilo Peçanha, lançou a semente do que, em 2008, veio constituir a Rede Federal de Educação Profissional, Científica e Tecnológica (RFEPCT): desde então são 38 Institutos Federais de Educação Profissional, Científica e Tecnológica (IF) espalhados por todo território nacional, além de 2 Centros Federais de Educação Tecnológica (CEFET), 23 Escolas Técnicas vinculadas às Universidades Federais, o Colégio Pedro Il e a Universidade Tecnológica Federal do Paraná ${ }^{2}$ (BRASIL, 2018).

No decurso do século $X X$, as instituições que compõem a RFEPCT destacaramse sobretudo pela oferta de ensino médio e técnico, estando os cursos de graduação restritos aos poucos CEFET, criados em alguns estados brasileiros, a partir da década de 1970. Mais tarde, nos anos 1990, com a "cefetização" das Escolas Técnicas Federais, os então CEFET passaram a oferecer cursos superiores e, em alguns casos, também de pós-graduação. Com a criação dos IF, em 2008, como política pública de expansão e fortalecimento da Educação Profissional e Tecnológica (EPT), estes, em conjunto com os dois CEFET e o Colégio Pedro II, passaram a ofertar à sociedade todas as modalidades e níveis de ensino, exceto a educação infantil e o ensino fundamental.

Diante da possibilidade da oferta da pós-graduação stricto sensu nos IF, nossa finalidade, neste artigo, é analisar o Programa de Pós-Graduação em Educação Profissional e Tecnológica (ProfEPT), Mestrado Profissional em Rede Nacional, considerando os avanços e os limites deste Programa para o alcance dos seus objetivos. Partimos da hipótese de que o ProfEPT é não apenas como uma grande conquista para a educação pública brasileira, mas, na mesma medida, também se constitui como um enorme desafio para as instituições ofertantes.

O artigo está dividido em duas seções. Na primeira, discutimos a expansão da pós-graduação stricto sensu na RFEPCT, e, nesse contexto, a criação do ProfEPT. Em seguida, apresentamos o ProfEPT, considerando seus números, expectativas e limitações a serem superadas.

OS IF E A OFERTA DE PÓS-GRADUAÇÃO STRICTO SENSU: o nascimento do PROFEPT

Por meio da Lei $n^{\circ}$ 11.892, de 29 de dezembro de 2008, o então presidente Luís Inácio Lula da Silva criou a Rede Federal de Educação Profissional, Científica e Tecnológica (RFEPCT) e os IF, caracterizados, conforme o Artigo Segundo dessa Lei, como:

[...] instituições de educação superior, básica e profissional, pluricurriculares e multicampi, especializadas na oferta de educação profissional e tecnológica nas diferentes modalidades de ensino, com base na conjugação de conhecimentos técnicos e tecnológicos com as suas práticas pedagógicas, nos termos desta Lei.

§ 1 Para efeito da incidência das disposições que regem a regulação, avaliação e supervisão das instituições e dos cursos de educação superior, os Institutos Federais são equiparados às universidades federais.

§ 2№ âmbito de sua atuação, os Institutos Federais exercerão o papel de instituições acreditadoras e certificadoras de competências profissionais.

$\S 3 \circ$ Os Institutos Federais terão autonomia para criar e extinguir cursos, nos limites de sua área de atuação territorial, bem como para registrar diplomas dos cursos por eles

\footnotetext{
Conforme Franco e Pereira (2017, p. 103-104), a UTFPR, "apesar de não ter oficializado sua desvinculação da RFEPCT, o que requereria alterar a Lei n 11.892/2008, não participa mais do Conselho Nacional das Instituições da Rede Federal de Educação Profissional, Científica e Tecnológica (Conif) nem da matriz orçamentária da Secretaria de Educação Profissional e Tecnológica do Ministério da Educação (Setec/MEC)”.
} 
oferecidos, mediante autorização do seu Conselho Superior, aplicando-se, no caso da oferta de cursos a distância, a legislação específica. (BRASIL, 2008, grifos nossos)

Como podemos perceber, a Lei $n^{\circ} 11.892 / 2008$ gera muitas expectativas a respeito dos IF: essas instituições ofertam educação superior, básica e profissional, igualam-se às universidades federais, podem criar e extinguir cursos. Não é de se surpreender que Pacheco (2011) veja os IF como uma revolução na EPT, pois é um "modelo institucional absolutamente inovador em termos de proposta político-pedagógica" e "têm suas bases em um conceito de educação profissional e tecnológica sem similar em nenhum outro país" (2011, p. 13). Por se constituírem em "espaços fundamentais na construção dos caminhos visando ao desenvolvimento local e regional", os IF "devem ir além da compreensão da educação profissional e tecnológica como mera instrumentalizadora de pessoas para ocupações determinadas por um mercado" (PACHECO, 2011, p. 14).

Nessa direção, Aguiar e Pacheco (2017, p. 15) afirmam que:

[...] os Institutos Federais, que não são a velha escola técnica, tampouco uma universidade, pois se caracterizam pela matriz marxista da indissociabilidade entre os compromissos de ordem prática e a compreensão teórica, são um ponto de convergência dos estudos teóricos, políticos e tecnológicos, com o claro objetivo de interpretar o mundo e transformá-lo.

Pacheco, Pereira e Domingos Sobrinho (2010, p. 75) resumem as reflexões de Pacheco (2011) e Aguiar e Pacheco (2017) e afirmam que os IF têm como um dos seus maiores desafios a construção de uma "formação profissional e do trabalho que ultrapasse o sentido da subordinação às restritas necessidades do mercado, contribua para o fortalecimento da cidadania dos trabalhadores e democratização do conhecimento em todos os campos e formas" (grifo nosso).

Para Pereira (2017), não há dúvidas de que os IF podem contribuir para o desenvolvimento do país, mas há muitos limites para que isso ocorra. Destaca a não consolidação dessas instituições e que a sua afirmação no Sistema Educacional Brasileiro depende da "combinação e a articulação de diversos fatores, dentre esses o reconhecimento, pelos diferentes atores envolvidos nesse processo, do papel estratégicos que essas instituições podem assumir no desenvolvimento e no fortalecimento da cidadania" (2017, p. 102). Por fim, alerta para a importância de "não considerar absoluto o poder dessas instituições e dos atores envolvidos nas escalas subnacionais. Antes, precisam ser olhadas de forma discreta, tendo em vista que se vive um período em que as decisões sobre desenvolvimento ultrapassam as escalas nacionais" (PEREIRA, 2017, p. 102-103).

Freitas et al (2017, p. 75) também veem avanços na criação dos IF, mas apontam alguns desafios para a EPT: "a necessidade de consolidação da expansão, a completa dependência de políticas públicas vigentes, a EPT como um campo de disputa política e conceitual e a necessidade de alinhamentos políticos pedagógicos". Ressaltam que "muito dessa dificuldade passa pela formação dos profissionais que adentraram na rede nos últimos 10 anos".

As ponderações dos autores supracitados não podem ser desconsideradas, caso observemos os dados quantitativos da RFEPCT, disponibilizados pela Secretaria de Educação Profissional e Tecnológica (SETEC) no site do MEC: "[...] a expansão e interiorização das instituições federais de EPT partiu, em 2006, de um total de 144 unidades. Chegou, em 2018, a 659 unidades em todo o país, das quais 643 já se encontram em funcionamento" (BRASIL, 2018). Logo, pari passu a esse crescimento, ampliamse também as dificuldades e os desafios para a Rede, haja vista que as instituições que dela fazem parte podem ofertar "[...] educação profissional e tecnológica (EPT) em todos os seus níveis e formas de articulação com os demais níveis e modalidades da Educação Nacional, oferta os diferentes tipos de cursos de EPT, além de licenciaturas, bacharelados e pós-graduação stricto sensu" (BRASIL, 2018). 
No que tange à pós-graduação, as investigações realizadas por Pereira e Rôças (2017), Alves et al (2017), Alves e Del Pino (2015), Franco e Pereira (2016), dentre outros pesquisadores, evidenciam um amplo crescimento e fomento à pós-graduação e à pesquisa na RFEPCT nas duas últimas décadas. Em função disso, Pereira e Rôças (2017, p. 168) observam que, com relação à pós-graduação stricto sensu, havia, em funcionamento nos IF, em 2017, 70 cursos, dos quais 20 eram de mestrados acadêmicos, 49 de mestrados profissionais e apenas um de doutorado.

A nova institucionalidade assumida pela RFEPCT, em 2008, traz, para si, uma preocupação: o baixo número de servidores com pós-graduação stricto sensu atestado no documento "Diretrizes para a atuação da Rede Federal de Educação Profissional, Científica e Tecnológica no Sistema Nacional de Pós-Graduação", elaborado por um grupo de consultores contratados pela SETEC. A partir desses dados, a SETEC chega a conclusão que é necessário

[...] induzir programas estratégicos de pós-graduação em educação profissional e tecnológica que articulem os cursos de mestrado profissional e o doutorado para profissionais como um eixo estruturante de formação, com identidade própria e avaliação adequada; apoiar a difusão de modalidades de pós-graduação em educação profissional e tecnológica com incentivos à criação e ao desenvolvimento de programas profissionais com recursos públicos e em parcerias público-privadas; valorizar, por meio de bolsas ou outros incentivos, a participação de profissionais no corpo docente dos cursos de educação profissional e tecnológica, estimulando a qualificação docente de profissionais atuantes em áreas estratégicas (BRASIL, 2015, p. 5).

O documento discutido na SETEC, em maio de 2015, deixa claro, em vários trechos, que a pós-graduação stricto sensu nos IF deve estar articulada às demandas das cadeias produtivas regionais e à inovação tecnológica, mas também deve colaborar para a melhoria do ensino fundamental e médio, em particular ao próprio ensino técnico e tecnológico. "Essa pós-graduação deve estruturar-se, predominantemente, em rede com caráter orgânico e forte capilaridade, maximizando o aproveitamento dos recursos humanos e materiais de todos os Institutos Federais participantes", observa a SETEC (BRASIL, 2015, p. 5).

No site do ProfEPT ${ }^{3}$, um histórico desse Programa relaciona suas origens à necessidade de qualificação profissional do quadro de servidores, haja vista que, com relação aos docentes, estes

[...] apresentam perfis os mais distintos possíveis: (a) docentes com alta titulação
acadêmica e pouca experiência junto ao setor produtivo, qualidade necessária à
EPT; (b) docentes com grande experiência junto ao setor produtivo e baixa titulação
acadêmica; (c) docentes que não tiveram formação pedagógica para atuação junto
à EPT; e (d) docentes que não foram capacitados para promover a integração do
ensino com as expectativas profissionais, sociais e econômicas da clientela que
atende e da região em que atua (INSTITUTO FEDERAL DE EDUCAÇÃO, CIEENCIA E
TECNOLOGIA DO ESPÍRITO SANTO, 2019)

Diante disso, e após discussões no Fórum dos Dirigentes de Pesquisa, PósGraduação e Inovação das Instituições da Rede Federal de Educação Profissional, Científica e Tecnológica (FORPOG), o Conselho Nacional das Instituições da Rede Federal de Educação Profissional, Científica e Tecnológica (CONIF) criou uma comissão que elaborou, em 2015, a proposta do Mestrado Profissional em Educação Profissional e Tecnológica (ProfEPT), apresentada à CAPES naquele ano, e aprovada em julho de 2016, após diligências documental e de visita (FREITAS; SOUZA, 2017).

A preocupação do CONIF com a formação dos servidores que compõem o quadro dos IF é procedente, como muito bem expressam Freitas e Souza (2017) e Freitas et al (2017). Aliás, importa destacar que esse tema é recorrente nos estudos de

Disponível em: https://profept.ifes.edu.br/sobreprofept Acesso em: 20 set. 2019. 
pesquisadores do campo da Educação Profissional e Tecnológica, a exemplo de Moura (2008), Araújo (2011), Kuenzer (2008), Machado (2008), Souza e Rodrigues (2017), dentre outros que investigam a formação do docente que atua nessa modalidade de educação e de ensino. Os autores salientam as formas aligeiradas como têm se dado os programas e projetos ditos como "especiais".

Nessa direção, o ProfEPT foi planejado "[...] no intuito, principalmente, de contribuir para a melhoria dos processos de ensino na EPT, por meio do desenvolvimento de pesquisas que gerem produção de conhecimentos relativos à área" (FREITAS et al, 2017, p. 76). Portanto, fica evidente a relação direta entre formação continuada e melhoria do ensino, pesquisa e extensão na Rede.

Elaborada a proposta, o CONIF submeteu à CAPES, o documento "Aplicativo de Propostas de Cursos Novos" (APCN), no qual encontramos várias justificativas para a criação do ProfEPT, dentre as quais merecem realce:

1 - O Plano Nacional de Pós-Graduação - PNPG 2011-2020 especialmente no que se refere às recomendações e diretrizes relacionadas: à ampliação da inter(multi)disciplinaridade na Pós-Graduação; ao combate às assimetrias regionais; à integração da Pós-Graduação com a Educação Básica; à formação de recursos humanos para empresas; e à formação de recursos humanos vinculados a Programas Nacionais.

2 - As Metas 10, 11, 13, 14 e 16 do Plano Nacional de Educação - PNE 2014-2024. Destacamos as três últimas por tratar: da elevação da qualidade da educação superior e ampliação do número de mestres e doutores em seu corpo docente (Meta 13); da elevação do número de matrículas na pós-graduação stricto sensu (Meta 14); e da formação, em nível de pós-graduação, de no mínimo $50 \%$ dos professores da educação básica, até o último ano de vigência do PNE (Meta 16).

3 - A possibilidade de o ProfEPT contribuir para o crescimento e o desenvolvimento da sociedade, o que pressupõe atividades que permitam, a priori, a ampliação de competências profissionais conjugadas com as demandas do setor produtivo, sem se perder de vista aspectos relativos à emancipação humana e à preparação para o exercício da cidadania em seus egressos.

Por fim, o APCN submetido à CAPES ressalta a necessidade de formar seu quadro de servidores:

\begin{abstract}
Essa realidade de necessidade de formação do seu próprio corpo de servidores levou à formulação dessa proposta de Curso de Mestrado Profissional em Rede Federal, que tem como premissa básica a necessária articulação de conhecimentos relativos ao mundo do trabalho e aos diversos conhecimentos científicos que compõem a área de ensino. Essa necessidade faz com que tenhamos em nossa proposta de curso um corpo docente com características interdisciplinares. Entendemos que somente assim conseguiremos nos aproximar da compreensão da complexidade que contempla o campo educação e trabalho e construir propostas educacionais que possam fazer diferença de forma positiva nos diversos espaços das instituições envolvidas, buscando trabalhar na perspectiva da integração curricular, tão desejável nos cotidianos escolares profissionalizantes. Dessa maneira, há a necessidade de termos no quadro de docentes desse mestrado profissionais que possuem sólida formação e pesquisas nas áreas de Educação e Ensino, no entanto também são necessários profissionais que compreendam as diversas áreas técnicas, a fim de se estabelecerem diálogos e propostas práticas para o ensino e para a gestão educacional (APLICATIVO DE PROPOSTAS DE CURSOS NOVOS, 2015, p. 7)
\end{abstract}

Em função disso, no Regulamento do ProfEPT, elaborado posteriormente à aprovação do curso, encontramos como seus objetivos: 
a) Atender à necessidade de formação continuada, numa perspectiva interdisciplinar e em nível de mestrado, voltada para profissionais da Rede Federal de Educação Profissional e Tecnológica a fim de desenvolverem atividades de ensino, gestão e pesquisa relacionados à educação profissional e tecnológica, na perspectiva de elaboração de produtos educacionais e materiais técnico-científicos com vistas à inovação tecnológica.

b) Atender à necessidade de desenvolvimento de trabalhos de investigação interdisciplinar, constituído pela interface entre Trabalho, Ciência, Cultura e Tecnologia, na perspectiva de melhoria dos processos educativos e de gestão em espaços formais ou não-formais.

c) Atender à demanda nacional por formação de recursos humanos em cursos de pósgraduação stricto sensu, com vistas ao desenvolvimento de pesquisas que integrem os saberes práticos inerentes ao mundo do trabalho ao conhecimento sistematizado e interdisciplinar, na perspectiva de contribuir com o desenvolvimento socioeconômico, científico e cultural nas diversas regiões do Brasil. (MESTRADO PROFISSIONAL EM EDUCAÇÃO PROFISSIONAL E TECNOLÓGICA EM REDE NACIONAL, 2017, p. 2)

Baseados no exposto, constatamos o compromisso do ProfEPT com a formação do quadro de servidores docentes e técnicos administrativos da RFEPCT, mas também com a de docentes que desenvolvem suas atividades na educação básica, sem desconsiderar a titulação de professores que atuam no ensino superior. Some-se a isso o empenho do Programa em desenvolver tecnologias para as regiões onde atua, considerando as demandas do setor produtivo.

\section{PROEPT: conquitas, expectativas e impasses}

Criado em 2016, o ProfEPT é um programa de pós-graduação recente, tendo formado, em agosto de 2019, a primeira turma, cuja entrada ocorreu em agosto de 2017. Logo, não é prudente fazermos uma avaliação aprofundada das ações que o Programa vem desenvolvendo. Tal fato nos leva a apenas apresentar algumas conquistas trazidas pelo Programa para o campo da EPT, as expectativas que ele tem gerado e os muitos impasses que tem enfrentado. Como esses três elementos estão imbricados, tentaremos discutir juntos.

O ProfEPT pertence à Área de Ensino da Capes e é ofertado nacionalmente pela RFEPCT. Suas atividades tiveram início em 2016, em 18 IF. Em 2017, foram credenciados mais 17 IF e o Colégio Pedro II e, em 2018, foram acrescidas mais 4 instituições (3 IF e o CEFET-MG), totalizando 40. O Programa hoje está presente em todos os estados brasileiros, possui aproximadamente 414 professores credenciados e 1.221 discentes regularmente matriculados ${ }^{4}$. Todos os alunos se submeteram ao Exame Nacional de Acesso (ENA), cujas vagas são divididas entre servidores da RFEPCT (50\%) e ampla concorrência (50\%).

Por conseguinte, é grande a visibilidade que o Programa tem trazido para a EPT como área de pesquisa, ao ampliar as investigações na pós-graduação. Salientamos também o destaque que esse mestrado tem dado ao campo de pesquisa sobre Trabalho e Educação, ao proporcionar leituras acerca de temas pouco explorados, mesmo pelos servidores da RFEPCT. Uma evidência disso, em termos quantitativos, pode ser atestada pelos ENA de 2017 (401 vagas), 2018 (820 vagas) e 2019 (908 vagas), para os quais se inscreveram, respectivamente, 26.410, 41.557 e 48.525 candidatos. A comparação entre o número de vagas e o quantitativo de candidatos inscritos, evidencia a grande demanda por pós-graduação no Brasil, mesmo tendo crescido a oferta desse nível de escolaridade nas últimas décadas.

Um fato não pode passar despercebido: as milhares de pessoas, no Brasil, estudando uma bibliografia sobre EPT, a maioria destas pela primeira vez na sua vida

Foram considerados, na época em que elaboramos este artigo, apenas os alunos selecionados pelo Exame Nacional de Acesso de 2017, com 401 vagas, e de 2018, com 820 vagas. A este número devem ser somados 908 candidatos aprovados no processo seletivo de 2019. 
acadêmica. A carência de leitura ou o total desconhecimento sobre o campo Trabalho e educação foi constatado em uma pesquisa que realizamos em junho de 2019 com alunos do ProfEPT de todas as regiões brasileiras. Foram obtidas 461 respostas de um total de 1.221 discentes (37,8\%), como podemos ver no Gráfico 1.

Gráfico 1: Nível de leitura acerca da Educação Profissional e Tecnológica

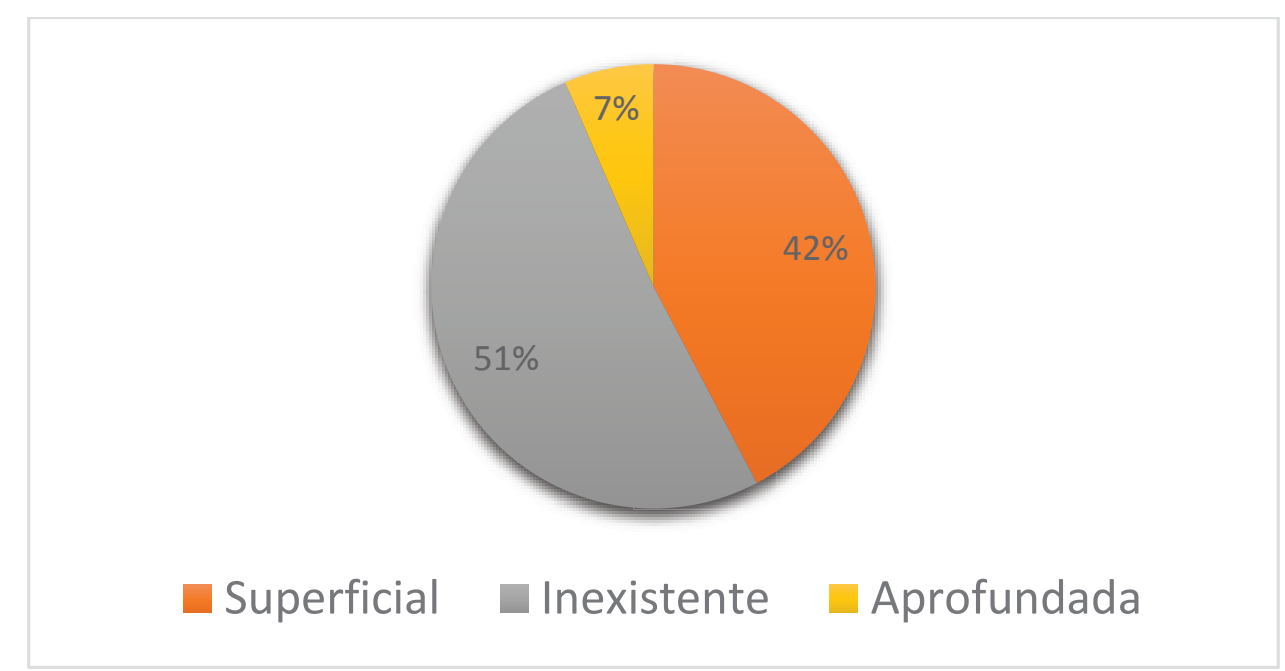

Fonte: Pesquisa realizada pelo autor (junho 2019).

O Gráfico 1 revela que apenas 7\% (30 alunos) consideram ter uma leitura aprofundada sobre a EPT. Caso somemos os $51 \%$, que avaliam como inexistente, aos $42 \%$, que afirmam ter estudos superficiais sobre esse tema, temos um total de $93 \%$ (431 alunos) que pouco ou nada conheciam sobre a EPT antes de ingressar no ProfEPT. A situação torna-se mais grave quando lembramos que um número considerável desse total é composto por docentes e técnicos administrativos da RFEPCT.

Diante desse cenário, é possível perceber o importante papel que ProfEPT tem dado para o abrandamento dessa realidade ao formar, até 2021 (ano previsto para a conclusão da terceira turma, com entrada em 2019), um número previsto de 2.129 mestres em EPT (considerando aqui o número de vagas dos editais de 2017, 2018 e 2019). Por conseguinte, podemos realçar não apenas o cumprimento de um dos objetivos do Programa, presente no APCN, mas ainda a sua importância para a execução da Meta 14 do Plano Nacional de Educação 2014-2024: "Elevar gradualmente o número de matrículas na pós-graduação stricto sensu, de modo a atingir a titulação anual de 60 mil mestres e 25 mil doutores" (BRASIL, 2015).

Além disso, ao formar esse número de mestres, o ProfEPT tem cooperado para a redução das disparidades regionais no Brasil no tocante à titulação em nível de mestrado, ainda concentrada no Sudeste do país, conforme o Plano Nacional de Educação 20142024. Nesse aspecto, é importante destacar que, para o ENA de 2019, ocorreram, de acordo com dados da Coordenação Nacional do Programa, inscrições de candidatos oriundos de 2.830 municípios brasileiros, portanto, mais de $50 \%$ dos 5.570 municípios.

Os discentes e os docentes do ProfEPT têm formação acadêmica em variadas áreas. Com relação aos professores, de acordo com dados fornecidos pela Coordenação Nacional do ProfEPT, a partir de uma pesquisa realizada em 2018, da qual participaram 371 docentes desse Programa, constatamos que aproximadamente $35 \%$ destes têm formação inicial bacharelesca, principalmente nas Engenharias. Os demais são licenciados e alguns têm as duas formações. Os Gráficos 2 e 3 destacam as titulações em níveis de mestrado e de doutorado, respectivamente. 
Gráfico 2: Formação dos docentes do ProfEPT em nível de mestrado (em \%)

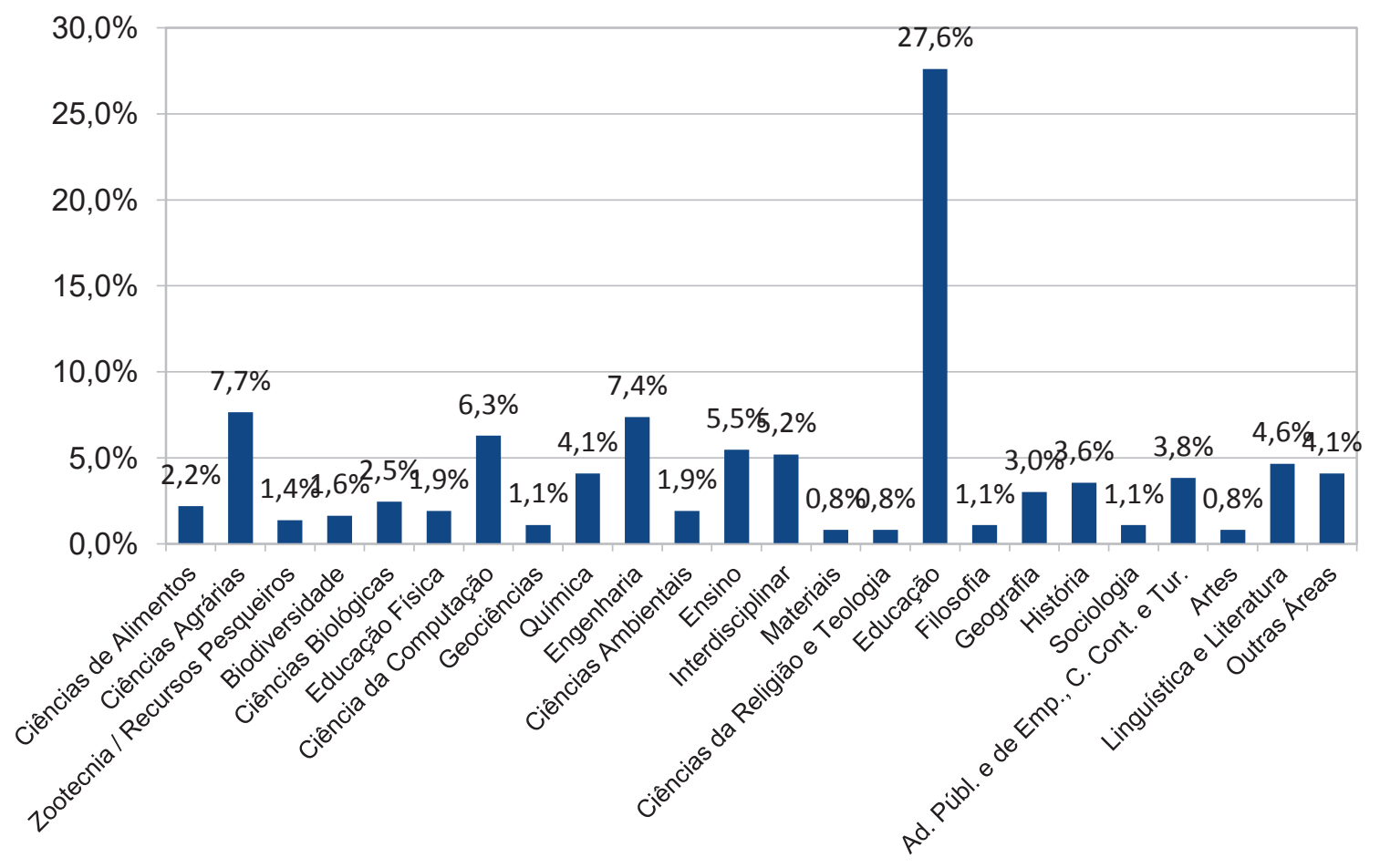

Fonte: Coordenação Nacional do ProfEPT (2018)

Gráfico 3: Áreas de formação dos docentes do ProfEPT em nível de doutorado (em \%)

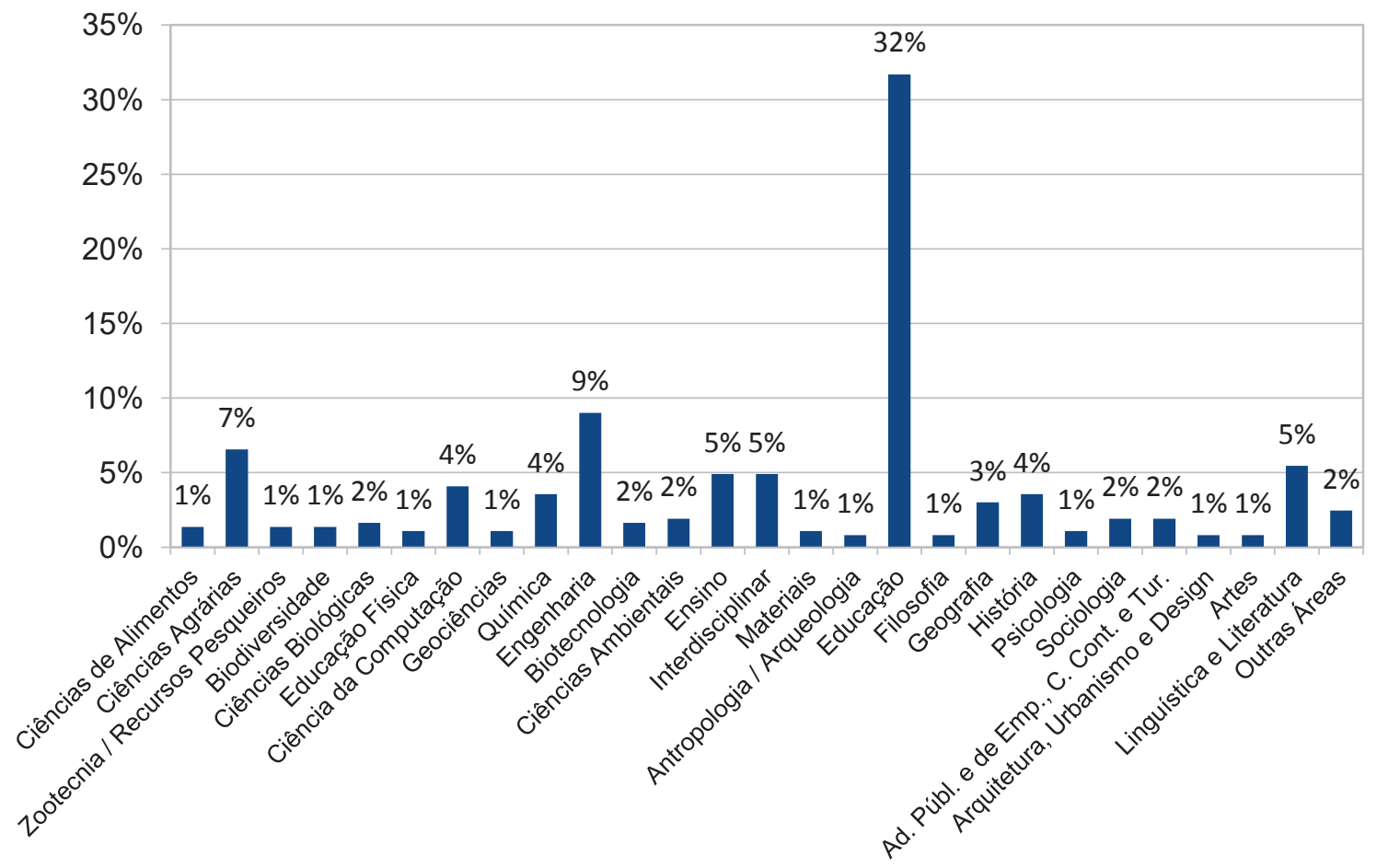

O resultado da pesquisa realizada pela Coordenação Nacional do ProfEPT demonstra um número elevado de docentes mestres e doutores em Educação, seguido pela Engenharia e pelas Ciências Agrárias. Percebemos ainda uma diversidade de formações: Linguística, Química, Ciências da Computação, História, Filosofia, Ciências Biológicas, dentre outras áreas de conhecimento.

No tocante à formação superior dos discentes, estas também são variadas, sendo predominante a área das Ciências Humanas, como podemos perceber no Gráfico 4: 


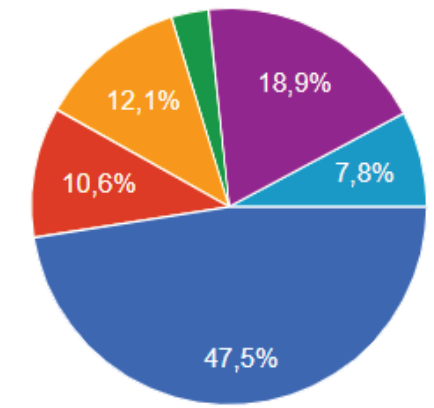

Nas Ciências Humanas

Nas Ciências Naturais e Exatas

Nas Ciências da Linguagem

Nas Engenharias

Nas Ciências Sociais Aplicadas

Nas Ciências da Saúde

Fonte: Pesquisa realizada pelo autor (junho 2019).

A priori, é importante ressaltar que a variedade de áreas de formação e de pesquisa dos docentes e discentes do ProfEPT é um aspecto positivo para esse Programa, pois possibilita o agrupamento de professores e alunos (bacharéis, tecnólogos e licenciados), na criação de projetos de ensino, pesquisa e de extensão de caráter interdisciplinar, apesar de reconhecermos as dificuldades para que isso ocorra satisfatoriamente. Nesse sentido, citamos o Prof. Rony Freitas, ex-coordenador nacional do ProfEPT:

\begin{abstract}
O reconhecimento da EPT como um espaço de múltiplas formações e de integrações necessárias entre elas faz com que nesse mestrado seja necessário um corpo docente multidisciplinar, o que pode possibilitar uma melhor compreensão da complexidade que contempla o campo trabalho e educação e a construção de propostas educacionais que façam diferença, de forma positiva, nos diversos espaços das instituições envolvidas, buscando trabalhar na perspectiva da integração curricular, tão desejável nos cotidianos escolares profissionalizantes. Dessa maneira, justifica-se a necessidade do quadro docente do ProfEPT ser constituído por profissionais que possuem sólida formação e pesquisas nas áreas de Educação e Ensino, mas também de profissionais que compreendam as diversas áreas técnicas, a fim de se estabelecerem diálogos e propostas práticas para o ensino e para a gestão educacional (FREITAS, 2019, p. 6-7).
\end{abstract}

No que tange à formação de docentes da Rede e de educação básica em geral, um dos objetivos do Programa presente no APCN submetida à CAPES e nos documentos elaborados nos encontros promovidos pela coordenação do ProfEPT, na pesquisa que realizamos com 461 alunos do ProfEPT das turmas de 2017 e 2018, 173 sujeitos afirmaram ser professores, conforme o Gráfico 5.

Gráfico 5: Atuação docente dos alunos do ProfEPT

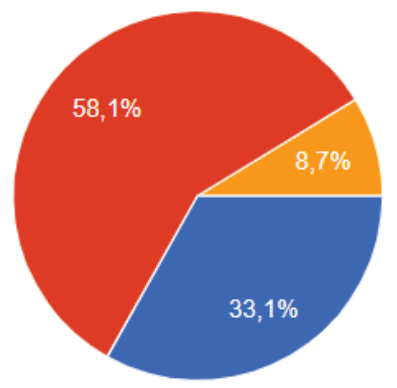

Na Rede Federal da Educação Profissional e Tecnológica.

Na Educação Básica da rede pública e/ou privada.

No Ensino Superior em outra instituição pública e/ou privada.

Fonte: Pesquisa realizada pelo autor (junho 2019).

O Gráfico 5 revela a contribuição que o ProfEPT tem dado para a titulação de docentes da educação básica, sejam estes pertencentes à RFEPCT ou à rede pública e privada, apesar de titular também docentes do ensino superior. Por outro lado, a pesquisa revela uma procura maior dos professores das redes públicas e privadas de educação básica. Nossa hipótese é de que já existe um número considerável de professores da RFEPCT que possuem mestrado e doutorado. De qualquer forma, podemos destacar o contributo do Programa para a elevação da qualidade da educação superior e para 
a ampliação do número de mestres e doutores em seu corpo docente (Meta 13); e da formação, em nível de pós-graduação, de no mínimo $50 \%$ dos professores da educação básica, até o último ano de vigência do PNE (Meta 16).

Um dado que não pode passar despercebido é que 288 dos 461 alunos entrevistados afirmaram não serem professores, indicando que o ProfEPT está capacitando mais técnicos administrativos da RFEPCT e das redes públicas, sejam de nível médio ou superior, do que docentes. Apesar desse fato ser visto, para muitos, como um problema ou desvio dos objetivos do Programa, merece ressalte o caráter educativo que possuem esses servidores em uma instituição de ensino.

Amparados em Tardife Levausseur(2011), observamos que, na contemporaneidade, há uma recomposição e divisão do trabalho educativo nas escolas, conduzindo a uma especialização e subdivisão nas funções de instruir, socializar e qualificar os alunos. Para esses autores, alguns técnicos trabalham diretamente com os alunos transmitindoIhes valores, regras, competências comunicacionais ou sociais, capacidade de reflexão, permitindo-lhes compreender o alcance de suas palavras e de seus gestos sobre os outros. Ou seja, ouvem os discentes, aconselham-nos sobre a vida pessoal, acadêmica, vida de futuros cidadãos e trabalhadores.

Todavia, se até aqui apontamos os aspectos positivos que o ProfEPT tem trazido e outros que se projetam para o futuro, não podemos cair em um otimismo simplista: os avanços que esse Programa trouxe e que promete são proporcionais às dificuldades a serem superadas. Destacamos três delas: a interdisciplinaridade, como pré-requisito para a formação integrada na educação básica, a elaboração de produtos educacionais que satisfaçam os objetivos expressos no APCN e no Anexo ao Regulamento do ProfEPT (2018), e o compromisso com a formação continuada de docentes para a EPT.

Quanto à interdisciplinaridade, esta tem sido tema em discussão no Brasil desde o final da década de 1960, mas "com sérias distorções, próprias daqueles que se aventuram ao novo sem reflexão, ao modismo sem medir as consequências do mesmo", como avalia Fazenda (2007, p. 33). Para a autora, nos anos 1990, a justificativa de que a ciência não se apoia apenas na objetividade, mas também subjetividade, levou ao aumento de projetos educacionais que se intitulam interdisciplinares, contudo estes "Surgem da intuição ou da moda, sem lei, sem regras, sem intenções explícitas, apoiando-se numa literatura provisoriamente difundida" (FAZENDA, 2007, p. 34).

Frigotto (2008) compreende a interdisciplinaridade como uma necessidade e um problema nas Ciências Sociais.

A necessidade da interdisciplinaridade na produção do conhecimento funda-se no caráter dialético da realidade social que é, ao mesmo tempo, una e diversa e na natureza intersubjetiva de sua apreensão, caráter uno e diverso da realidade social nos impõe distinguir os limites reais dos sujeitos que investigam dos limites do objeto investigado. Delimitar um objeto para a investigação não é fragmentá-lo, ou limitá-lo arbitrariamente. Ou seja, se o processo de conhecimento nos impõe a delimitação de determinado problema, isto não significa que tenhamos que abandonar as múltiplas determinações que o constituem. É neste sentido que mesmo delimitado um fato teima em não perder o tecido da totalidade de que faz parta indissociável (FRIGOTTO, 2008, p. 43-44, grifos do autor).

Para o autor em tela, "os homens ao produzirem sua existência mediante as diversas relações e práticas sociais o fazem enquanto uma unidade que engendra dimensões biológicas, psíquicas, intelectuais, culturais, estéticas, etc." (FRIGOTTO, 2008 , p. 45). Dessa forma, o pesquisador não pode perder de vista que a sua análise só será adequada, se considerar a relação do seu objeto com as demais dimensões.

Contudo, para Frigotto (2008), a interdisciplinaridade é também um problema. Primeiramente, porque o sujeito que busca conhecer uma determinada realidade é limitado e não consegue exaurir todos os seus aspectos, levando-o sempre a construir 
um conhecimento relativo, parcial e incompleto. Ademais, o plano material-histórico e cultural traz limites para a produção de um conhecimento interdisciplinar. Isso porque: "A cisão que se produz e desenvolve no plano das relações de produção do homem social, enquanto uma totalidade concreta, se explicitam necessariamente no plano da consciência, das representações e concepções da realidade" (FRIGOTTO, 2008, p. 50). E continua: "A classe que tem à disposição os meios de produção material controla concomitantemente os meios de produção intelectual, de sorte que, por essa razão, geralmente as ideias daqueles que carecem desses meios ficam subordinadas a ela". Por conseguinte, para o autor, "[...] a produção e a divulgação do conhecimento não se faz alheia aos conflitos, antagonismos e relações de forças que se estabelecem entre as classes ou grupos sociais (sic.)" (2008, p. 51). Por fim, Frigotto (2008, p. 52-53) alerta:

\begin{abstract}
A não atenção ao tecido histórico dentro do qual se produz o conhecimento e as práticas pedagógicas, tem nos levado a tratar a questão da interdisciplinaridade dentro de uma ótica fenomênica, abstrata e arbitrária. Aparece como sendo um recurso didático capaz de integrar, reunir as dimensões particulares dos diferentes campos científicos ou dos diferentes saberes numa totalidade harmônica. Não há, dentro deste prisma didatista nenhum problema em fazer-se, no dizer de Lefevre, sopa metodológica (Grifos do autor).
\end{abstract}

Ciavatta (2015) e Ramos (2008) endossam a percepção de Frigotto (2008) sobre a interdisciplinaridade como necessidade e como problema. Para Ciavatta, a interdisciplinaridade "[...] não se trata apenas de uma justaposição disciplinar, de um somatório de aspectos, mas da compreensão dos diferentes aspectos articulados como produção social em um tempo e em um espaço determinados" (2015, p. 58). Dessa forma, para ela, a formação integrada, uma das bandeiras de luta de muitos educadores brasileiros, não pode ser confundida com interdisciplinaridade.

\begin{abstract}
A ideia de formação integrada remete ao sentido de aproximação das partes, dos campos do saber, das formas de conhecimento, das classes sociais. Os dois conceitos, interdisciplinaridade e formação integrada, não tem o mesmo sentido de completude. É possível dizer que a interdisciplinaridade é uma condição favorável, mas não suficiente para a formação integrada, salvo se incorporar os elementos sociais e políticos da formação como um todo (CIAVATTA, 2008, p. 64).
\end{abstract}

Ramos (2008), ao tratar da concepção de Ensino Médio Integrado, faz referências ao conceito de interdisciplinaridade a partir de Santomé e Bernstein. Salienta que a sua proposta de integração incorpora elementos trazidos por esses dois autores, mas os ultrapassam "ao definir de forma mais clara as finalidades da formação: possibilitar às pessoas compreenderem a realidade para além de sua aparência fenomênica". Nessa perspectiva, "os conteúdos de ensino não têm fins em si mesmos nem se limitam a insumos para o desenvolvimento de competências. Os conteúdos de ensino são conceitos e teorias que constituem sínteses da apropriação histórica da realidade material e social pelo homem" (2008, p. 17).

Dois pressupostos teóricos embasam a organização curricular defendida por Ramos (2008, p. 17): o primeiro é "a concepção de homem como ser histórico-social que age sobre a natureza para satisfazer suas necessidades e, nessa ação, produz conhecimentos como síntese da transformação da natureza e de si próprio"; o segundo compreende que "a realidade concreta é uma totalidade, síntese de múltiplas relações. Totalidade significa um todo estruturado e dialético, do qual ou no qual um fato ou conjunto de fatos pode ser racionalmente compreendido pela determinação das relações que os constituem".

Certamente, isso explica a amplitude que tem a ideia de interdisciplinaridade no campo educacional, embora isso não ocorra com tanta visibilidade nas práticas pedagógicas, como salienta Ciavatta (2015). Provavelmente, isso ocorra pelo fato de que a ideia de interdisciplinaridade, segundo Fazenda (2003, p. 64): 
[...] é norteada por eixos básicos como: a intenção, a humildade, a totalidade, o respeito pelo outro etc. O que caracteriza uma prática interdisciplinar é o sentimento intencional que ela carrega. Não há interdisciplinaridade se não há intenção consciente, clara e objetiva por parte daqueles que a praticam. Não havendo intenção de um projeto, podemos dialogar, inter-relacionar, e integrar sem, no entanto, estar trabalhando interdisciplinarmente. A apreensão da atitude interdisciplinar garante, para aqueles que a praticam, um grau elevado de maturidade. Isso ocorre devido ao exercício de uma certa forma de encarar e pensar os acontecimentos. Aprende-se com a interdisciplinaridade que um fato ou solução nunca é isolado, mas sim consequência de muitos outros.

Diante disso, resta-nos questionar se os professores e alunos do ProfEPT, com formações tão diversas e que tiveram (em sua maioria) uma formação disciplinar, cartesiana, ainda presente na academia (sobretudo nas chamadas "Ciências duras"), estão abertos às práticas do discurso da inovação pedagógica e às leituras sobre outras áreas do conhecimento. A indagação que se faz é: a interdisciplinaridade tem sido assumida por esse público ou ainda não foi superado o seu caráter de projeto sem reflexão ou modismo do final da década de 1960? Em que medida o discurso interdisciplinar tem sido posto em prática? São questionamentos que, por enquanto, não temos como responder, mas apenas abrir para a reflexão.

Além do desafio da prática interdisciplinar, um outro, relacionado a este, diz respeito aos produtos educacionais que os mestrandos e professores orientadores devem apresentar, no ProfEPT, como condição básica para a conclusão do curso de Mestrado Profissional.

Consoante Moreira (2004), há quatro ações que a pós-graduação stricto sensu deve contribuir significativamente para as transformações necessárias: 1- A formação de professores dos ensinos fundamental e médio (esses docentes devem também serem multiplicadores); 2- A formação de profissionais que possam atuar de forma adequada em: desenvolvimento e implementação curricular, coordenação e orientação, e nos diversos processos de avaliação próprios do sistema escolar; 3- A formação de docentes das disciplinas "de conteúdo" das licenciaturas nas áreas específicas; e 4- A formação de professores de ensino superior para disciplinas "de conteúdo" em cursos de graduação em instituições. Para Moreira, essas ações justificam a necessidade de Mestrados Profissionais na área de Ensino.

O ProfEPT pertence à Área de Ensino, a qual se caracteriza por ser de pesquisa translacional e "que busca construir pontes entre conhecimentos acadêmicos gerados em educação e ensino para sua aplicação em produtos e processos educativos na sociedade" (COORDENAÇÃO DE APERFEIÇOAMENTO DE PESSOAL DE NÍVEL SUPERIOR, 2013, p. 1). Assim, seguindo as orientações da CAPES, o ProfEPT deve gerar produtos educacionais que serão disponibilizados para uso em escolas públicas do país, além das dissertações e artigos derivados do relato descritivo e analítico dessas experiências.

Portanto, a perspectiva é que, a partir de 2019, o ProfEPT gere centenas de produtos educacionais que ficarão disponíveis para professores e alunos da educação básica de todo o país, os quais poderão adaptá-los à realidade local, significando um grande avanço em termos de experiência de ensino-aprendizagem em uma área carente desse tipo de material. Pautamo-nos aqui na finalidade do mestrado profissional, destacado por Moreira (2004, p. 133): "requer que se encontre naquele trabalho [o produto educacional] uma proposta de ação profissional que possa ter, de modo mais ou menos imediato, impacto no sistema a que ele se dirige" (grifo do autor).

Os produtos educacionais "podem ser entendidos como artefatos de ensinoaprendizagem na disposição dos conteúdos disciplinares" (POSSOLI; CURY, 2009 apud MOREIRA et al, 2017, p. 2559). Eles possuem diferentes nomenclaturas (materiais educativos, objetos de aprendizagem, material didático, dentre outros tipos), assumem, 
na sua produção, consumo e circulação, formatos diversos: impressos (livros, apostilas etc.), audiovisuais, recursos digitais e outros; e resultam da pesquisa nos mestrados profissionais, tendo como fim a disseminação e análise por professores com intuito de ser utilizado na prática escolar.

Segundo Rôças (2017), em Conferência no $1^{\circ}$ Seminário deAlinhamento Conceitual do ProfEPT, em São Paulo, esses produtos "devem suprir algumas das funções atribuídas ao professor, além de oferecer oportunidades e espaços para diálogo com as partes envolvidas e com o próprio material". A pesquisadora destaca também que "Todo produto educacional deve ser criado de acordo com o público, devendo ser discutido, criticado, reelaborado, nos diversos momentos coletivos e individuais que integram o planejamento e a execução das atividades propostas para o ensino" (Grifos da autora). Reforça que devem "Utilizar metodologias de ensino que insiram o público-alvo de forma participativa no processo de ensino-aprendizagem". Logo, precisa "Considerar o papel do sujeito nesse processo, bem como seus conhecimentos prévios. Para tal, devemos elaborar situações de ensino contextualizadas que privilegiam a participação do público na reconstrução do conhecimento".

Nesse sentido, voltamos a destacar os grandes desafios que o ProfEPT assume quando da geração desses produtos, haja vista que a maioria dos professores desse Programa é egressa de mestrados e doutorados acadêmicos e, assim, não tem familiaridade com esse tipo de produção. Podemos supor que tal desconhecimento possa levar muitos desses produtos a não terem as características salientadas por Rôças e outros autores anteriormente citados. Além disso, poderão também não fazer relação com as bases conceituais que fundamentam a concepção de EPT defendida por esse mestrado, mesmo que elas sejam estudadas em uma das disciplinas obrigatórias no primeiro semestre do curso.

Baseados nessa conjectura, a criação de produtos educacionais voltados para o Ensino Médio Integrado (EMI), uma das grandes bandeiras dos pesquisadores do campo Trabalho e educação, pode vir a ter limitações quanto aos princípios orientadores da prática pedagógica nessa forma de articulação entre o ensino propedêutico e o profissional. Frisamos que os produtos educacionais voltados para o EMI, além de considerar a interdisciplinaridade como elemento essencial para a formação integrada (CIAVATTA, 2015), não devem desconsiderar as orientações do Documento Base da Educação Profissional Técnica de Nível Médio Integrada ao Ensino Médio (BRASIL, 2007) e das Diretrizes Curriculares Nacionais para a Educação Profissional Técnica de Nível Médio (BRASIL, 2013).

O primeiro documento, publicado em 2007, explicita os princípios e diretrizes do EMI e norteia a implementação da política, subsidiando a formação docente, a produção dos currículos e a materialização da proposta nas escolas. Elenca como concepções e princípios do EMI: 1- a formação humana integral; 2- trabalho, ciência, tecnologia e cultura como categorias indissociáveis da formação humana; 3- o trabalho como princípio educativo; 4- a pesquisa como princípio educativo; 5- a relação partetotalidade na proposta curricular (BRASIL, 2007).

A integração entre o Ensino Médio e a formação técnica almeja uma proposta curricular que se oponha à histórica dualidade estrutural da educação brasileira. Para Ramos (2005), essa integração se constrói a partir do estabelecimento das relações entre os conhecimentos gerais e os técnicos, necessitando de uma organização curricular que:

a) conceba o sujeito como ser histórico-social concreto, capaz de transformar a realidade em que vive; b) vise à formação humana como síntese de formação básica e formação para o trabalho; c) tenha o trabalho como um princípio educativo no sentido de que o trabalho permite, concretamente, a compreensão do significado econômico, social, histórico, político e cultural das ciências e das artes; d) seja baseado numa epistemologia que considere a unidade de conhecimentos gerais e conhecimentos específicos e de uma metodologia que permita a identificação das especificidades 
desses conhecimentos quanto à sua historicidade, finalidades e potencialidades; e) seja baseado numa pedagogia que vise à construção conjunta de conhecimentos gerais e específicos, no sentido de que os primeiros fundamentam os segundos e esses evidenciam o caráter produtivo concreto dos primeiros; f) seja centrado nos fundamentos das diferentes técnicas que caracterizam o processo de trabalho moderno, tendo como eixos o trabalho, a ciência e a cultura. (RAMOS, 2005, p. 108109).

Convém destacar que a proposta de EMI apresentada por Ramos (2005) e por outros estudiosos do campo Trabalho e Educação (destaque para Kuenzer, Ciavatta, Frigotto, Moura, Machado), encontra seus fundamentos filosóficos, epistemológicos e pedagógicos nas bases teórico-conceituais da omnilateralidade e da politecnia, presentes nos escritos de Marx e Engels, e da escola unitária, presente nos estudos de Gramsci.

O segundo documento, as Diretrizes Curriculares Nacionais para a Educação Profissional Técnica de Nível Médio, tem o mundo do trabalho como referência. Reconhece que "A educação para o trabalho não tem sido tradicionalmente colocada na pauta da sociedade brasileira como um direito universal". Porém, ela tem sido associada unicamente à formação de mão de obra, "reproduzindo o dualismo existente na sociedade brasileira entre as 'elites condutoras' e a maioria da população trabalhadora" (BRASIL, 2013 , p. 208). Conforme esse documento, a complexidade do mundo do trabalho "exige a transformação das aprendizagens em saberes integradores da prática profissional". Desse modo, "A escolha por um determinado fazer deve ser intencionalmente orientada pelo conhecimento científico e tecnológico. Este, por sua vez, não deve ser ensinado de forma desconectada da realidade do mundo do trabalho" (BRASIL, 2013, p. 212).

As Diretrizes Curriculares Nacionais para a Educação Profissional Técnica de Nível Médio retomam alguns princípios presentes no Documento Base para o EMI pois, ao tratar da EPT, afirmam a necessidade de superação do dualismo entre a formação propedêutica e a profissional, e a prática de uma formação humana que envolva trabalho, ciência, tecnologia e cultura, o trabalho como princípio educativo, e a pesquisa como princípio pedagógico. Ademais, tendo em vista a redução da grande desigualdade de acesso à educação, as Diretrizes buscam articular ao Ensino Médio, a Educação de Jovens e Adultos, a profissionalização de pessoas com deficiência, transtornos globais do desenvolvimento e altas habilidades, a educação escolar indígena, a educação escolar quilombola e a educação do campo (BRASIL, 2013).

A esses desafios assumidos pelo ProfEPT, acrescentamos outro de grande Ldimensão: o compromisso assumido pelo Programa em formar professores para a EPT. Reconhecemos como uma árdua tarefa a oferta de formação continuada para servidores da RFEPCT e demais interessados em estudar nesse Programa, geralmente oriundos de graduação em áreas diversas e até vistas, por muitos, como opostas. É fato que, nos variados ambientes que ofertam EPT (sejam nas esferas pública ou privada, ou ainda em espaços não formais) há um número elevado de bacharéis, sem formação pedagógica e, muitos, sem experiência profissional. Há também, muitos profissionais licenciados, todavia, com pouca (ou nenhuma) formação nos estudos no campo do Trabalho e Educação. Diante desse cenário, Freitas et al (2017, p. 78) defendem a necessidade do estabelecimento de um diálogo "para que tenhamos um processo educacional que realmente consiga promover uma formação em sentido amplo, que possa contribuir para o fortalecimento dos diversos ambientes de trabalho, e que, acima de tudo, consiga ajudar na formação crítica e cidadã dos estudantes".

Com finalidade semelhante, Machado (2008, p. 18) observa que o profissional a ser formado para a EPT deve:

[...] ter capacidade para elaborar estratégias; estabelecer formas criativas de ensinoaprendizagem; prever as condições necessárias ao desenvolvimento da educação profissional, considerando suas peculiaridades, as circunstâncias particulares e as 
situações contextuais em que se desenvolve; realizar um trabalho mais integrado e interdisciplinar; promover transposições didáticas contextualizadas e vinculadas às atividades práticas e de pesquisa.

Contudo, as limitações para essa formação tornam-se evidentes quando consideramos os grupos a que ela se destina. Para Moura (2008, p. 31):

[...] temos que considerar, no mínimo, três situações distintas quanto aos grupos aos quais se destina essa formação. Em primeiro lugar, os profissionais não graduados que já atuam na EPT. Em segundo, os graduados que já atuam como docentes da EPT, mas não têm formação específica nessa esfera educacional; e os futuros profissionais que já estão em formação superior inicial. Finalmente, os futuros profissionais que ainda começarão a formação superior inicial.

Diante do exposto, chegamos ao questionamento feito por Marx e Engels em "A Ideologia Alemã", na terceira tese de Feuerbach: "[...] o educador tem ele próprio que ser educado (1999, p. 12)". O grande impasse que se coloca ao ProfEPT é: quem educará os educadores? Isso depende de se ir "além dos conhecimentos específicos de cada formação, se conhecer os fundamentos filosóficos e históricos da Educação Profissional, as relações especiais entre o contexto de ação, pedagógica ou não, e a sua formação profissional, bem como os currículos envolvidos", como salientam Freitas et al (2017, p. 75).

Face ao exposto, pensamos que uma resposta dada por Saviani a um questionamento no Seminário "Choque Teórico", realizado no Politécnico de Saúde Joaquim Venâncio, no Rio de Janeiro, em 1987, venha nos dar uma expectativa otimista quanto às limitações que enfrenta o ProfEPT. Destacou o educador:

\footnotetext{
O que me parece importante salientar é o seguinte: é preciso constituir determinadas estruturas, porque é a realidade que determina a consciência e não o contrário. Às vezes temos a tendência a uma certa visão idealista, de acreditar que primeiro é preciso mudar a mentalidade, primeiro ter consciência da coisa, para depois agir. Ora, é preciso criar determinadas estruturas concretas, que de alguma forma direcionem essa transformação, pois a própria mentalidade se transforma nesse contato prático. Não vejo maiores problemas em partir disso: aliás, acho que se tem que partir do existente, não posso partir do nada. Sempre me vem à tona uma frase de Marx: "Para se ter uma educação transformada, é preciso uma sociedade transformada, e para se ter uma sociedade transformada, é preciso ter uma educação transformada". Aí ele acrescenta: é preciso, pois, partir da situação atual (1989, p. 31-32).
}

Portanto, é assim que devemos pensar o ProfEPT: uma ação construída, ainda com muitos desafios, dúvidas internas, indefinições... mas, em contrapartida, temos um Programa em Rede que suscita e amplia leituras acerca de uma modalidade educativa, até pouco tempo, desconhecida para muitos e que propõe uma transformação que enseja uma ressignificação em seu interior.

\section{Considerações finais}

Neste artigo, o ProfEPT é apresentado como um avanço para a RFEPCT e para a formação de docentes e demais servidores que atuam na educação básica, além atingir também o ensino superior. Não há como negar a oportunidade que esse Programa tem dado a centenas de pessoas que realizam o sonho de uma pós-graduação stricto sensu. Ademais, os seus números mostram a capilaridade que esse mestrado tem atingido ao atender todo o território nacional e ter inscritos, em seus processos seletivos de muitos municípios brasileiros, a exemplo do ENA de 2019, para o qual se inscreveram candidatos de mais de $50 \%$ do total de municípios.

Por outro lado, os desafios impostos ao ProfEPT são igualmente imensos: a diversidade de formações acadêmicas, tanto dos docentes quanto de discentes, 
podem, ao invés de ajudar, impedir a elaboração de projetos interdisciplinares; a dificuldade de criação de produtos educacionais com aderência às linhas de pesquisa do Programa e fora das bases em que se assentam a EPT; o incremento às práticas inovadoras e da pesquisa como princípio educativo, dentre tantos outros limites.

Em contrapartida, para além dos avanços e dos desafios (alguns intransponíveis a curto prazo), temos um Programa que está crescendo e aprendendo com seus erros e acertos em um contexto de dificuldades econômicas, cortes no orçamento, restrição de liberdade de expressão, rebatimentos na perspectiva política da escola no sentido da formação de um trabalhador cidadão emancipado. Essa conjuntura nos impede de fazer projeções muito otimistas. Não sabemos se o ProfEPT conseguirá sobreviver às adversidades e manter a sua linha teórica de contra hegemonia à formação restrita aos interesses do mercado. Mas, como nos diz lucidamente Saviani (1989): lutemos para criar as estruturas concretas, que de alguma forma, direcionem o caminho da transformação.

\section{REFERÊNCIAS}

AGUIAR, L. E. V.; PACHECO, E. M. Os Institutos Federais de Educação, Ciência e Tecnologia como política pública. In: ANJOS, M. B.; RÔÇAS, G. As políticas públicas e o papel social dos Institutos Federais de Educação, Ciência e Tecnologia. Editora IFRN: Natal, 2017. p. 12-34.

ALVES, C. G. M.; DEL PINO, J. C. A atuação dos IFs frente ao Sistema Nacional de PósGraduação - um comparativo entre 2008-2014. Holos, Natal, v. 5, p. 379-400, 2015. DOI: 10.15628/holos.2015.3090

ALVES, C. G. M. et al. Institutos Federais de Educação, Ciência e Tecnologia como lócus de formação de professores da educação básica no contexto da oferta de pós-graduação stricto sensu. Contrapontos, Itajaí, v. 17, n. 1, p. 117-137, jan./abr. 2017.

ARAÚJO, R. M. L. Formação de docentes para a Educação Profissional e Tecnológica: por uma pedagogia integrada da educação profissional. Trabalho \& Educação, Belo Horizonte, v. 17, n. 2, p. 53-63, maio/ago. 2008.

BRASIL. Educação Profissional Técnica de Nível Médio Integrada ao Ensino Médio: documento base. Brasília, 2007. Disponível em: http://portal.mec.gov.br/setec/arquivos/ pdf/documento_base.pdf. Acesso em: 15 set. 2019.

BRASIL. Lei No 11.892, de 29 de dezembro de 2008. Institui a Rede Federal de Educação Profissional, Científica e Tecnológica, cria os Institutos Federais de Educação, Ciência e Tecnologia, e dá outras providências. Brasília, 2008. Disponível em: http://www.planalto.gov.br/ccivil_03/_Ato2007-2010/2008/Lei/L11892.htm Acesso em: 15 set. 2019.

BRASIL. Ministério da Educação. Secretaria de Educação Profissional e Tecnológica. Diretrizes para a atuação da Rede Federal de Educação Profissional, Científica e Tecnológica no Sistema Nacional de Pós-graduação. Brasília: Ministério da Educação. 2015. 25f. Documento para discussão.

BRASIL. Ministério da Educação. Expansão da Rede Federal. Brasília, set. 2018. Disponível em: http://portal.mec.gov.br/setec-programas-e-acoes/expansao-da-rede-federal. Acesso em: 15 set. 2019.

BRASIL. Diretrizes Curriculares Nacionais para a Educação Profissional Técnica de Nível Médio. In: BRASIL. Diretrizes Curriculares Nacionais Gerais da Educação Básica. Brasília: MEC, SEB, DICEI, 2013. p. 202-265. 
BRASIL. Instituto Nacional de Estudos e Pesquisas Educacionais Anísio Teixeira. Plano Nacional de Educação PNE 2014-2024: Linha de Base, Brasília: Inep, 2015.

CONSELHO NACIONAL DAS INSTITUIÇÕES DA REDE FEDERAL DE EDUCAÇÃO PROFISSIONAL, CIENTÍFICA E TECNOLÓGICA (CAPES). Documento de Área 2013. Brasília, 2013. 80f.

CONSELHO NACIONAL DAS INSTITUIÇÕES DA REDE FEDERAL DE EDUCAÇÃO PROFISSIONAL, CIENTÍFICA E TECNOLÓGICA (CAPES). Aplicativo de Propostas de Cursos Novos (APCN). Mestrado Profissional em Educação Profissional e Tecnológica. Brasília, 2015. $195 f$.

CIAVATTA, M. A. O trabalho docente e os caminhos do conhecimento: a historicidade da Educação Profissional. Rio de Janeiro: Lamparina, 2015.

FAZENDA, I. C. A. Interdisciplinaridade: história, teoria e pesquisa. 14. ed. Campinas: Papirus, 2007.

FAZENDA, I. C. A. Interdisciplinaridade: qual o sentido? São Paulo: Paulus, 2003.

FRANCO, F. S. C.; PEREIRA, J. L. A. R. A evolução da pós-graduação na Rede Federal. In: SOUZA, R. R. (Org). Pesquisa, pós-graduação e inovação na Rede Federal de Educação Profissional, Científica e Tecnológica, Goiânia: IFG, 2017. p. 103-128.

FREITAS, R. C. O. et al. O Mestrado Profissional em Educação Profissional e Tecnológica em Rede Nacional: considerações preliminares. Educação Profissional e Tecnológica em Revista, Vitória, v. 1, n. 1, p. 74-89, 2017.

FREITAS, R. C. O.; SOUZA, R. R. Mestrado em Educação Profissional e Tecnológica: uma construção em rede. In: SOUZA, R. R. (Org). Pesquisa, pós-graduação e inovação na Rede Federal de Educação Profissional, Científica e Tecnológica, Goiânia: IFG, 2017. p. 157178.

FREITAS, R. C. O. Desafios da pós-graduação em Educação Profissional e Tecnológica (entrevista concedida a Eduardo Augusto Werneck Ribeiro, Inge Renate Frose Suhr e Bruno Nunes Batista). Debates em educação, Maceió, abr. 2019.

FRIGOTTO, G. A interdisciplinaridade como necessidade e como problema nas Ciências Sociais. Ideação, Foz do Iguaçu, v. 10, n. 1, p. 41-62, 2008.

INSTITUTO FEDERAL DE EDUCAÇÃO, CIÊNCIA E TECNOLOGIA DO ESPÍRITO SANTO. Programa de Pós-Graduação em Educação Profissional e Tecnológica. Mestrado Profissional em Rede Nacional. O ProfEPT: histórico, Vitória, 2019. Disponível em: https://profept.ifes.edu. br/sobreprofept. Acesso em: 27 jul. 2019.

KUENZER, A. Z. Formação de professores para educação profissional e tecnológica: perspectivas históricas e desafios contemporâneos. Educação Superior em Debate, Brasília: Instituto Nacional de Estudos e Pesquisas Educacionais Anísio Teixeira, v. 8, p. 19-40, 2008.

MACHADO, L. R. S. Diferenciais inovadores na formação de professores para a educação profissional. Revista Brasileira da Educação Profissional e Tecnológica, Brasília, DF, MEC, SETEC, v. 1, n. 1, p. 8-22, jun. 2008.

MARX, K; ENGELS, F. A ideologia alemã. 11 ed. São Paulo: Hucitec, 1999.

MESTRADO PROFISSIONAL EM EDUCAÇÃO PROFISSIONAL E TECNOLÓGICA EM REDE NACIONAL. Regulamento. Vitória, 2015. Disponível em: https://profept.ifes.edu.br/ regulamentoprofept/regu. Acesso em: 19 set. 2019. 
MESTRADO PROFISSIONAL EM EDUCAÇÃO PROFISSIONAL E TECNOLÓGICA EM REDE NACIONAL. Anexo ao Regulamento. Vitória, 2018. Disponível em: https://profept.ifes.edu.br/ regulamentoprofept/anexoregulamentogeral. Acesso em: 19 set. 2019.

MOREIRA, M. A. O mestrado (profissional) em ensino. Revista Brasileira de Pós-Graduação, Brasília, v. 1, n. 1, p. 131-142, 2004.

MOREIRA, M. C. A. et al. A interdisciplinaridade em produtos educacionais de um mestrado profissional em ensino de ciências. Enseñanza de las ciencias: revista de investigación y experiencias didácticas, Barcelona, p. 2.559-2.564, set. 2017.

MOURA, D. H. A formação de docentes para a educação profissional e tecnológica. Revista Brasileira da Educação Profissional e Tecnológica, Brasília, DF, MEC, SETEC, v. 1, n. 1, p. 23-38, jun. 2008.

PACHECO, E. Os Institutos Federais: uma revolução na educação profissional e tecnológica. In: PACHECO, E. (Org.). Os Institutos Federais: uma revolução na educação profissional e tecnológica. São Paulo: Moderna, p. 13-32, 2011.

PACHECO, E.; PEREIRA, L. A. C.; DOMINGOS SOBRINHO, M. Institutos Federais de Educação, Ciência e Tecnologia: limites e possibilidades. Linhas críticas, Brasília, v. 16, n. 30, p. 71-88, jan./jun. 2010.

PEREIRA, L. A. C. A expansão da Rede Federal de Educação Profissional e Tecnológica e os Institutos Federais no contexto regional: diálogos com o desenvolvimento. Educação Profissional e Tecnológica em Revista, Vitória, v. 1, n. 1, p. 90-104, 2017.

PEREIRA, M. V.; RÔÇAS, G. O ensino de pós-graduação nos Institutos Federais. In: ANJOS, M. B.; RÔÇAS, G. As políticas públicas e o papel social dos Institutos Federais de Educação, Ciência e Tecnologia. Editora IFRN: Natal, 2017. p. 160-178.

RAMOS, M. N. Possibilidades e desafios na organização do currículo integrado. In: FRIGOTTO, G.; CIAVATTA, M.; RAMOS, M. (Org.). Ensino Médio Integrado: concepções e contradições. São Paulo: Cortez, 2005. p. $106-127$.

RAMOS, M. N. Concepção do ensino médio integrado, Belém, 2008. Disponível em: http:// forumeja.org.br/go/sites/forumeja.org.br.go/files/concepcao_do_ensino_medio_integrado5.pdf Acesso em: 19 set. 2019.

RÔÇAS, G. Produtos da pesquisa em ensino: cenário atual, desafios e perspectivas. SEMINÁRIO DE ALINHAMENTO CONCEITUAL DO PROFEPT, 1, São Paulo, maio. 2017. (Conferência). Disponível em: https://www.youtube.com/watch?v=XiHGOUVR1fA> Acesso em: 16 set. 2019.

SAVIANI, D. Sobre a concepção de politecnia. Rio de Janeiro: Fiocruz, 1989.

SOUZA, F. C. S.; RODRIGUES, I. S. Formação de professores para educação profissional no Brasil: percurso histórico e desafios contemporâneos. Revista HISTEDBR On-line, Campinas, v.17, n. 2, p. 621-638, abr./jun. 2017.

TARDIF, M.; LEVAUSSEUR, L. A divisão do trabalho educativo. Petrópolis: Vozes, 2011. 